The Egyptian Journal of Hospital Medicine (January 2018) Vol. 70 (11), Page 1992-1999

\title{
The Prevalence of Neck Pain and The Relationship Between Prolonged Use of Electronic Devices and Neck Pain IN: A Saudi Arabia, Cross- Sectional Study in Saudi Arabia

\author{
Abdulrahman Nasser Alzaid, Omar Abdulmohsen Alshadokhi,Abdulrahman Yousef Alnasyan, \\ Meshal Yahya AlTowairqi,Tariq Majed Alotaibi,Faisal Hammad Aldossary \\ Imam Mohammed bin Saud Islamic University
}

\begin{abstract}
Background: Since the use of smartphones has increased recently, their impact on people individual's health is not well established.It is important and critical to examine and discover the presence, absence or the magnitude of this impact, especially among young people, because the pediatrics in certain communities constitutes $>25 \%$.

Aim of the work: determination of the prevalence of neck pain among children/adolescents and its relationship with time spent using electronic devices (e-devices).

Material and methods: This cross-sectional study was conducted in Saudi Arabia using an online google survey form, which was distributed through social media to 2435 participants to find out the prevalence of neck pain among pediatric population and its relationship with e-devices use .

Results:Our study showed that roughly a quarter of the participants in Saudi Arabia have pediatric population having neck pain, and mostpediatric sufferers are between 15-18 years. More time spent using e-devices was associated with increased complaints of neck pain, specifically, children at the age of 7-11 years spending 5-8 hours/day on e-devices. Around $70 \%$ had an aching pain that required them to ask for Doctor's.

Conclusion: The research sample reported that children's use of electronic devices showed a close association with neck pain and the more the child spends time using an electronic device the greater is the complaint of neck pain. We found that there is a positive correlation between long time smart devices use and neck pain.
\end{abstract}

Keywords: neck pain, children, e-devices, duration of time.

\section{INTRODUCTION}

In the last few years, smart phones and electronic devices (e-devices; smartphones, computers, and others) have been become widely spread among many communities and across all ages.However, their effect on human physical and mental health still a dilemma is not known. An American study (2017) had concluded that $77 \%$ of the American population in 2017 are using smart phones, a dramatic increase from 33\% that was reported in $2011^{(\mathbf{1})}$. According to the Saudi general authority for statistic in 2017 the Saudi age group (0-19) years in Saudi Arabia constituting 39.1\% of the Saudi population, and for all population (Saudi and non-Saudi) of the same age group they constitute $31.6 \%{ }^{(2)}$.

Poor neck posture (forward head posture) is noticed while using smartphones, which may lead to neck pain. Neck pain has a broad range of differential diagnosis is ranging from benign to live- threatening causes (e.g., trauma, infection, malignancy) and, many researches have established a correlation between neck pain and the use of smart devices ${ }^{(3,4)}$. A cross- sectional study in

Received: 20/12/2017

Accepted: 30/12/2017
Finland showed that neck pain occurs at least once a week in

approximately $26 \%$ of the population aged 14-18 years-old ${ }^{(5)}$. Another cross-sectional study was held in England with 679 schoolchildren aged 1214 years showed that $27 \%$ of the children reported neck pain at least one day per month ${ }^{(6)}$. Another cross-sectional study of in Shanghai with 3600 high school students aged 15-18 years held on Shanghai showed significant increases in neck and back pain for four days or more a month among those who were using digital products-devices (7). Lastly, another cross-sectional study was conducted in Riyadh, Saudi Arabia at King Saud University with 78 participants (with mean age of 21.3 years), the result showed a clear association between prolonged usage of smart phones and neck pain ${ }^{(8)}$.

Therefore, we thought to hold a cross-sectional study in Saudi Arabia using google survey introduced through the social media and 2435 participants responded. The target population was pediatrics from 0-18 year. The aim of this study is to determine the prevalence of neck pain and to assess the relationship between prolonged use of smart 
devices and neck pain among children in Saudi Arabia.

\section{METHODS}

In July 2017, we conducted an online, crosssectional survey through using social media networks by putting a link to an electronic survey and distributing the link on various. The survey was written in Arabic language targeting children who live in the Kingdom of Saudi Arabia from age 18 years old and below. There were no exclusion criteria .

In our questionnaire, we asked about participants' age; and whether they are using Edevice, and, if so, for how long and also what the position they prefer to use their device.

Then, we asked if they complained of neck pain and, if so, they complained, did they think if the pain was related to using e-device. We also asked, whether they went to a clinic for this pain or not.Also if they have any medical problem(s) that might produce this pain (e.g. congenital disease). Finally, we asked them if they tried to limit the usage of e-device to reduce the pain. About 2435 respondents are included.

The study was done after approval of ethical board ofImam Mohammed Bin Saud Islamic university.

\section{RESULTS}

The Two thousand four hundred thirty five individuals responded to our questionnaire. All of them were living in Saudi Arabia and aged 18 years and below. Participant's characteristics are presented in Table. 1 and Figure 1.

$955(39.2 \%)$ of the responding were by mothers while 591(24.3\%) were by brothers and sisters. The fathers had presented $375(15.4 \%)$ of the responding. 324(13.3\%) of the answers were by uncles and aunts.Also 190(7.8\%) were taken from other relatives. Children males participated more than females, and they were acting 1409 (57.9\%) of our sample, while females represented 1026(42.1\%) of the total. Most of our sample are between 7-11 years old and they are 901(37\%). While a few are between 15-18 years old and they were $348(14.3 \%)$. Then comes in the second place of our sample between the age of 5-6 with a number of $457(18.8 \%)$ followed by those whose age is between 12-14 years old with a number of $368(15.1 \%)$. Finally, less than 4 years represent $361(14.8 \%)$ of the total .

Most of our participants who use e- device, allocate 5-8 hours per day and represent $760(31.2 \%)$, while who use it for 2-4 hours a day represent $659(27.1 \%)$. About $400(16.4 \%)$ of the users spentless than 2 hours a day on e- device. 812 hours per day are spent by $364(14.9 \%)$ of the users. On the other hand, the lowest percentage of the users $252(10.3 \%)$ are using the e-device for more than 12 hours.

However, the participants prefer using e- devise in sitting position more than standing position.Thus, there were 1899 (78\%) who were using e-device in sitting position.

\section{Gender distribution among the participants}


Figure 1: gender distribution among the respondents.

Table 1. Participants' demographic characteristics Breakup of participants who live in Saudi $(\mathrm{N}=2435)$

\begin{tabular}{|c|c|c|c|}
\hline & Characteristic & Number & Percentage \\
\hline \multirow{5}{*}{ Relation to the child } & Mother & 955 & 39.2 \\
\hline & Brother/sister & 591 & 24.3 \\
\hline & Father & 375 & 15.4 \\
\hline & Uncle/aunt & 324 & 13.3 \\
\hline & Other & 190 & 7.8 \\
\hline \multirow{4}{*}{ Age (years) } & $4<\geq$ & 361 & 14.8 \\
\hline & $5-\overline{6}$ & 457 & 18.8 \\
\hline & $7-11$ & 901 & 37 \\
\hline & $12-14$ & 368 & 15.1 \\
\hline \multirow{2}{*}{ Sex } & Male & 1409 & 57.9 \\
\hline & Female & 1026 & 42.1 \\
\hline \multirow{5}{*}{$\begin{array}{c}\text { Time spent using an } \\
\text { e-device }\end{array}$} & $<2$ hours a day & 400 & 16.4 \\
\hline & $2-4$ hours a day & 659 & 27.1 \\
\hline & $5-8$ hours a day & 760 & 31.2 \\
\hline & 8-12 hours a day & 364 & 14.9 \\
\hline & $>12$ hours a day & 252 & 10.3 \\
\hline \multirow{3}{*}{$\begin{array}{l}\text { Preferred physical } \\
\text { position }\end{array}$} & Sitting & 1899 & 78 \\
\hline & Standing & 30 & 1.2 \\
\hline & Other & 506 & 20.8 \\
\hline \multirow{2}{*}{ Experiencing pain } & $\mathrm{No}$ & 1858 & 76.3 \\
\hline & Yes & 577 & 23.7 \\
\hline
\end{tabular}

The characteristics of those who had neck pain are shown in Table 2. Of 2435 participants, $577(23.7 \%)$ are complaining of neck pain; the large segment of neck pain complainers are males with a number of $325(56.3 \%)$, while $252(43.7 \%)$ are females.

Table 2. Characteristics of participants with neck pain. Breakup of participants who had neck pain $(\mathrm{N}=577)$

\begin{tabular}{|c|c|c|}
\hline Characteristic & Number & Percentage \\
\hline \multicolumn{3}{|c|}{ Believes pain is caused by using e-devices } \\
\hline Yes & 540 & 94.2 \\
\hline No & 33 & 5.8 \\
\hline \multicolumn{3}{|c|}{ The child has a medical problem(s) that causes this pain } \\
\hline No & 574 & 99.5 \\
\hline Yes & 3 & 0.5 \\
\hline \multicolumn{3}{|c|}{ Visited a medical clinic because of this pain } \\
\hline Yes & 422 & 73.1 \\
\hline No & 155 & 26.9 \\
\hline \multicolumn{3}{|c|}{ Those who tried to limit their child's use of e-devices because of neck pain } \\
\hline Yes & 443 & 76.8 \\
\hline
\end{tabular}




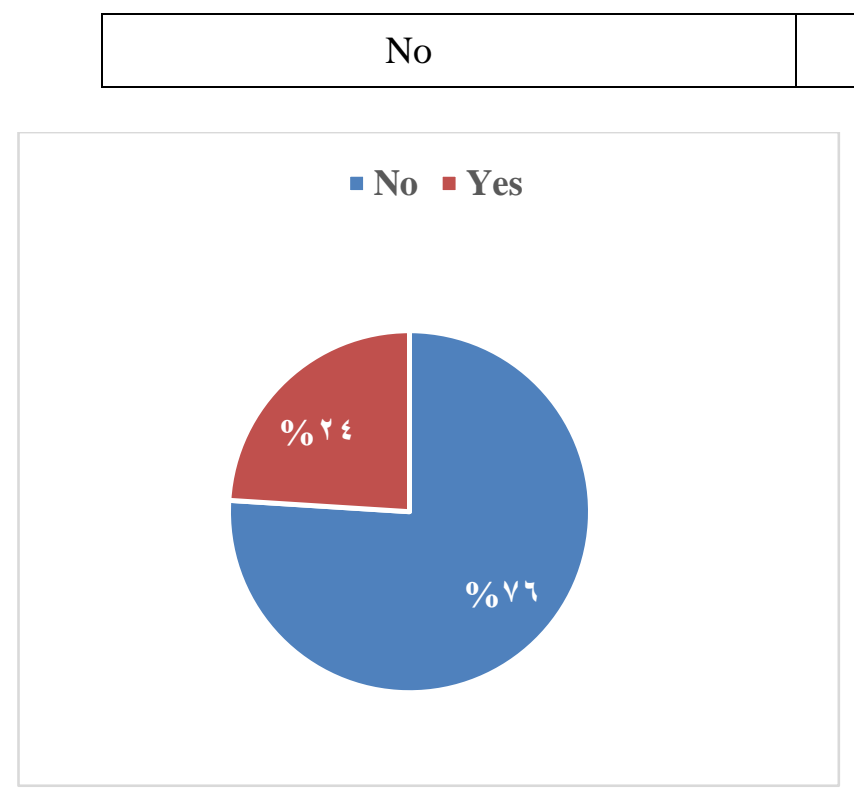

Fig. (2): the distribution of included subjects according to feeling pain during exercise

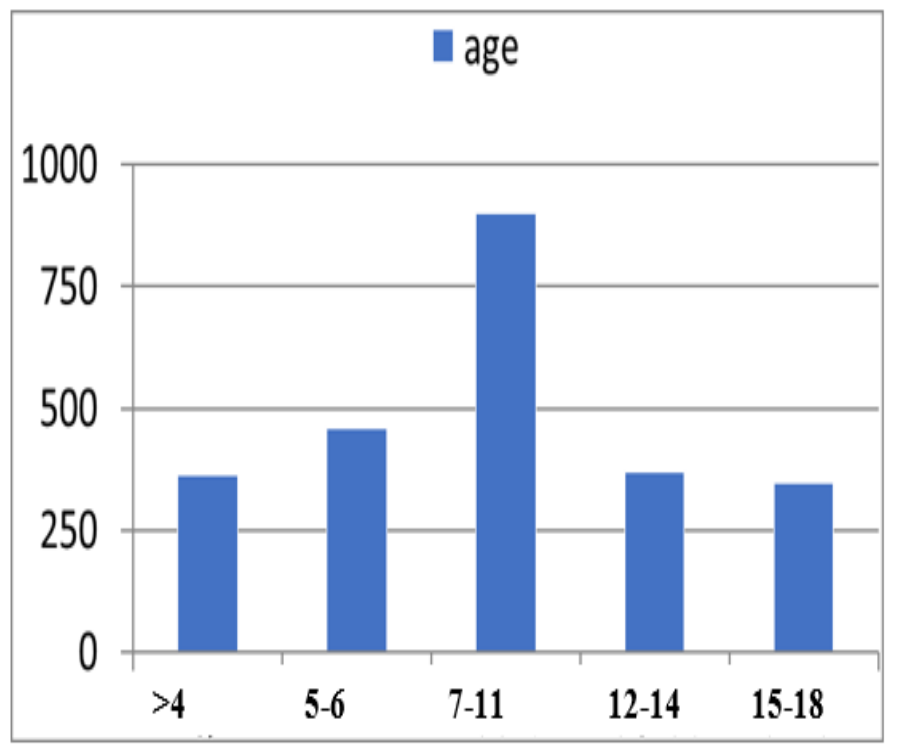

Fig(3): show the distribution of age among studied participants

\begin{tabular}{l|r}
134 & 23.2 \\
\hline
\end{tabular}

$\begin{array}{ll}\square<2 \text { hours a day } & \quad 2-4 \text { hours a day } \\ \square 5-8 \text { hours a day } & \quad 8-12 \text { hours a day } \\ \square>12 \text { hours a day } & \end{array}$

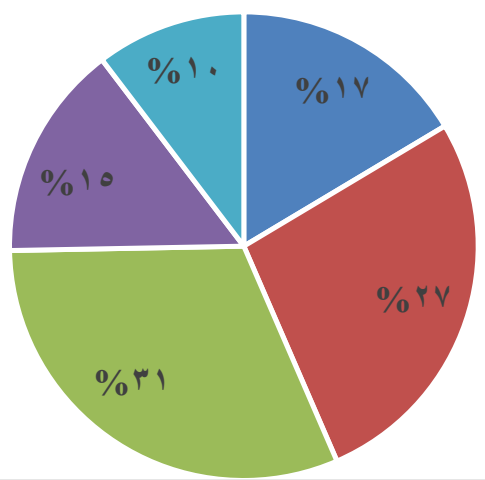

Fig. (4): distribution of the study participants according to time spent using an e-device

Participants experienced neck pain and its association with age, posture, and usage are shown in Table 3.After breaking down the ages of the participants, we found that the highest number of the neck pain complainers is around the ages 7-11 years old with a number of 206(35.7\%) . Participants whose age is less than 4 years old, are considered as the lowest affected by the e-device with a number of $30(5.2 \%)$.

The second highest number of the affected participants is between 15-18 years old with a number of 171(29.6\%), followed by the complainers at the age of 12-14 with a number of $105(18.2 \%)$ as the fourth most affected. Participants who are 5-6 years old present only $11.3 \%$ of the total affected. $94.2 \%$ of them were thinking that using e-device is the main reason to cause this pain, while $5.8 \%$ did not agree with that. Only 3 children suffered from medical problems that produce this pain. $73.1 \%$ of the participants visited medical clinics because of this pain. For those who, agreed that e-device is the main reason, $443(76.8 \%)$ tried to limit the usage of e-device to reduce the pain. 
Table 3. Participants experienced neck pain and its association with age, posture, and usage

\begin{tabular}{|c|c|c|c|c|}
\hline & \multirow{2}{*}{ Variant } & \multicolumn{2}{|c|}{ Pain } & P-value \\
\hline & & Yes & No & \\
\hline \multirow{2}{*}{ Sex } & Male & $325(56.3)$ & $1084(58.3)$ & \multirow{2}{*}{$<.001$} \\
\hline & Female & $252(43.7)$ & $774(41.7)$ & \\
\hline \multirow{3}{*}{ Position } & Sitting & $444(76.9)$ & $1455(78.3)$ & \multirow{3}{*}{$<.045$} \\
\hline & Standing & $4(0.7)$ & $26(1.4)$ & \\
\hline & Other & $129(22.4)$ & $377(20.3)$ & \\
\hline \multirow{5}{*}{ Age (years) } & $<\leq 4$ & $30(5.2)$ & $331(17.8)$ & \multirow{5}{*}{$<.001$} \\
\hline & $5-6$ & $65(11.3)$ & $392(21.1)$ & \\
\hline & $7-11$ & $206(35.7)$ & $695(37.4)$ & \\
\hline & $12-14$ & $105(18.2)$ & $263(14.2)$ & \\
\hline & $15-18$ & $171(29.6)$ & $177(9.5)$ & \\
\hline \multirow{5}{*}{ Usage time } & $<2$ hours a day & $28(4.9)$ & $372(20)$ & \multirow{5}{*}{$<.001$} \\
\hline & 2-4 hours a day & $128(22.2)$ & $531(28.6)$ & \\
\hline & 5-8 hours a day & $193(33.4)$ & $567(30.5)$ & \\
\hline & 8-12 hours a day & $103(17.9)$ & $261(14)$ & \\
\hline & $>12$ hours a day & $125(21.7$ & $127(6.8)$ & \\
\hline
\end{tabular}

Most of the participants (193-33.4\%) who are complaining of neck pain allocate 5-8 hours per day for using the e-device. However, Only $28(4.9 \%)$ use it less than 2 hours a day. The second highest segment of the users complaining of neck pain 128(22.2\%) selected 2-4 hours per day to use the e- device. Almost the same number of the users $125(21.7 \%)$ have allocated 4-6 hours a day to use the e-device. Participants, who used the e-device more than 12hours per day were $103(17.9 \%)$.

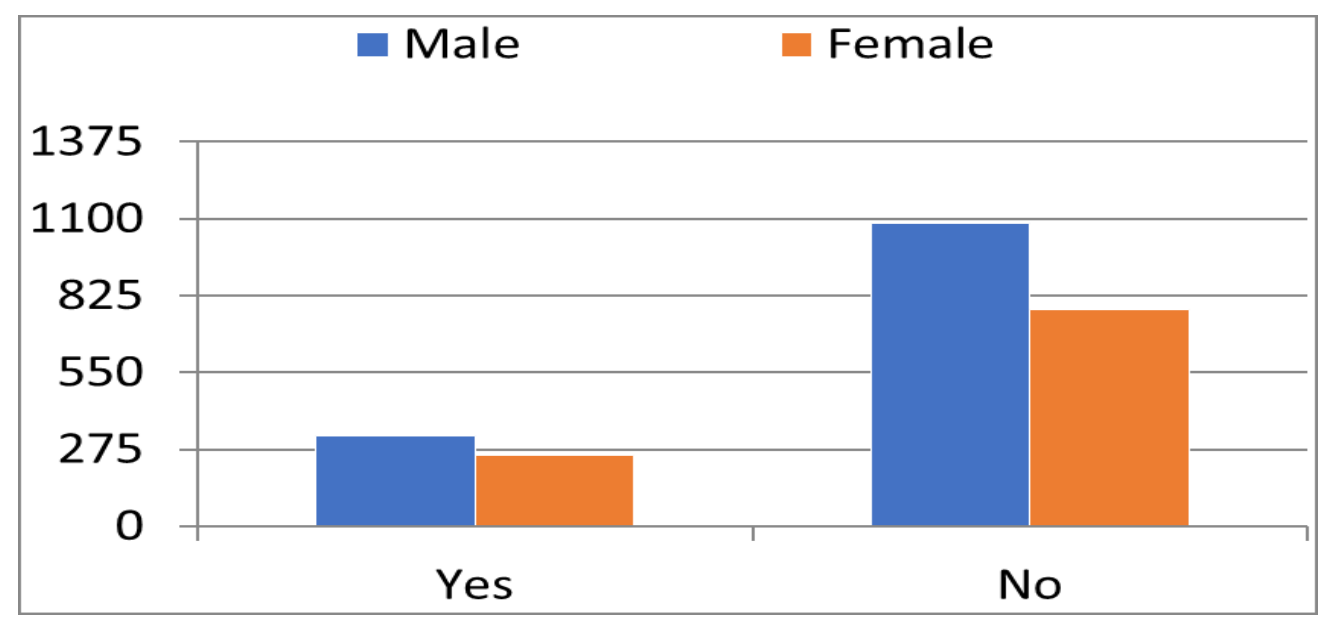

Fig. (5): distribution of neck pain according to different gender

Anyway, most of our sample who are complaining of neck pain prefered to use e- device with the sitting position, they were $444(76.9 \%)$ while, $4(0.7 \%)$ prefered using it standing. The rest of theparticipants who complaining of neck pain 129
(22.4\%) chose a different position to use the edevice.

On the other hand, those who were not complaining of neck pain represented 1858 (76.3\%) of our sample. The large segment of non- 
complainers were males with a number of 1084 $(58.3 \%)$, while774 (41.7\%) were females

For those who did not have neck pain, we found that, the highest number of users are between the age of 7-11with a number of 695 (37.4\%). Participants whose age is around 15-18 years old considered as the lowest users of e-device with a number of $177(9.5 \%)$. The second having the highest number of the users participants was those whoseage is between 5-6 years with a numberof $392(21.1 \%)$, followed by the complainers less than 4 years old(17.8\%). Participants who are 12-14 years old represented $263(14.2 \%)$ of the total users.
Most of our participants who werenot complaining of neck pain using e- device, have allocated 5-8 hours per day and they were representing 567(30.5\%), while the users of the edevice for 2-4 hours a day represented 531(28.6\%). $372(20 \%)$ of the users spent less than 2 hours a day. 8-12 hours per day were spent by $261(14 \%)$ of the users. On the other hand, the lowest percentage of the users are using the e-device for more than 12 hours were $127(6.8 \%) .1455(78.3 \%)$ preferred to use e- device with the sitting position. while, $26(1.4 \%)$ preferred to use e-device standing. The rest of the participants 377 (20.3\%) chose a different position to use the e-device.

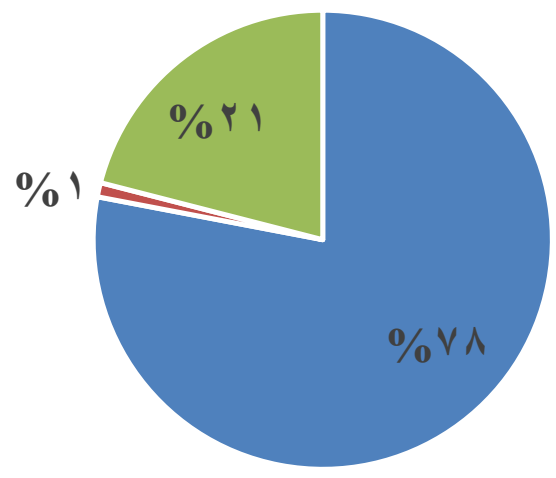

- Sitting

- Standing

- Other

Fig. (6): Distribution of neck pain among studied participants according to position Note. All values are represented as $n(\%)$; p-values $<0.05$ are considered significant.

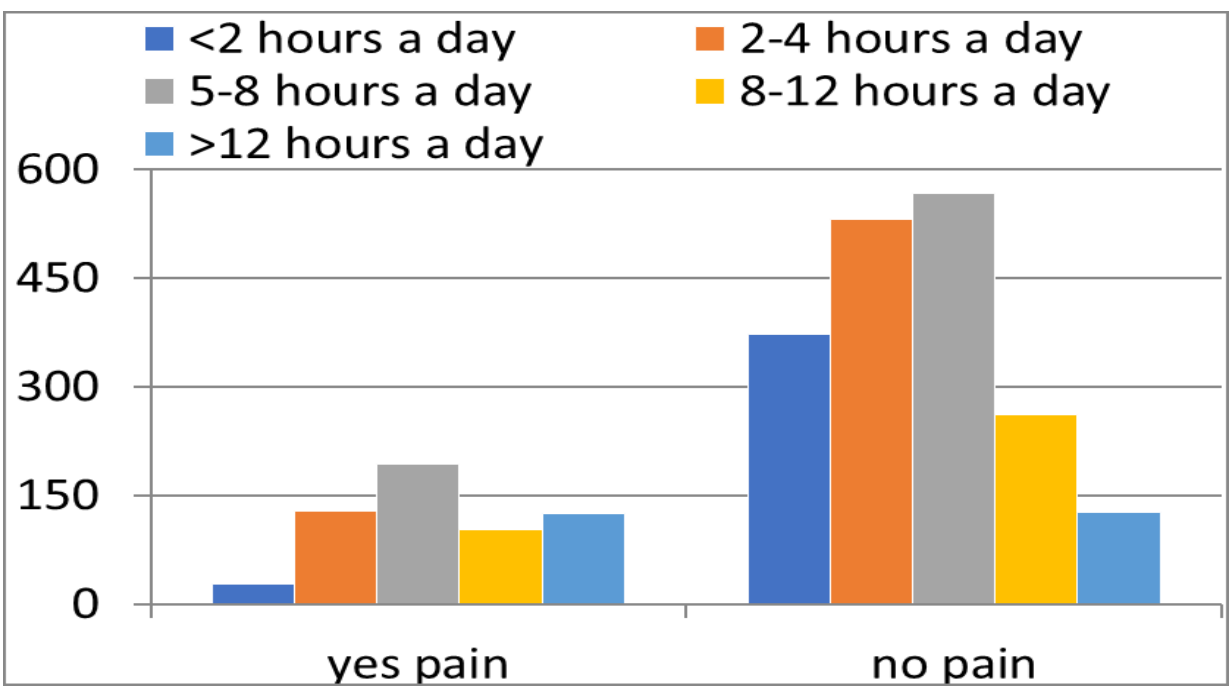

Fig. (7): Distribution of neck pain among studied participants according to usage hours 


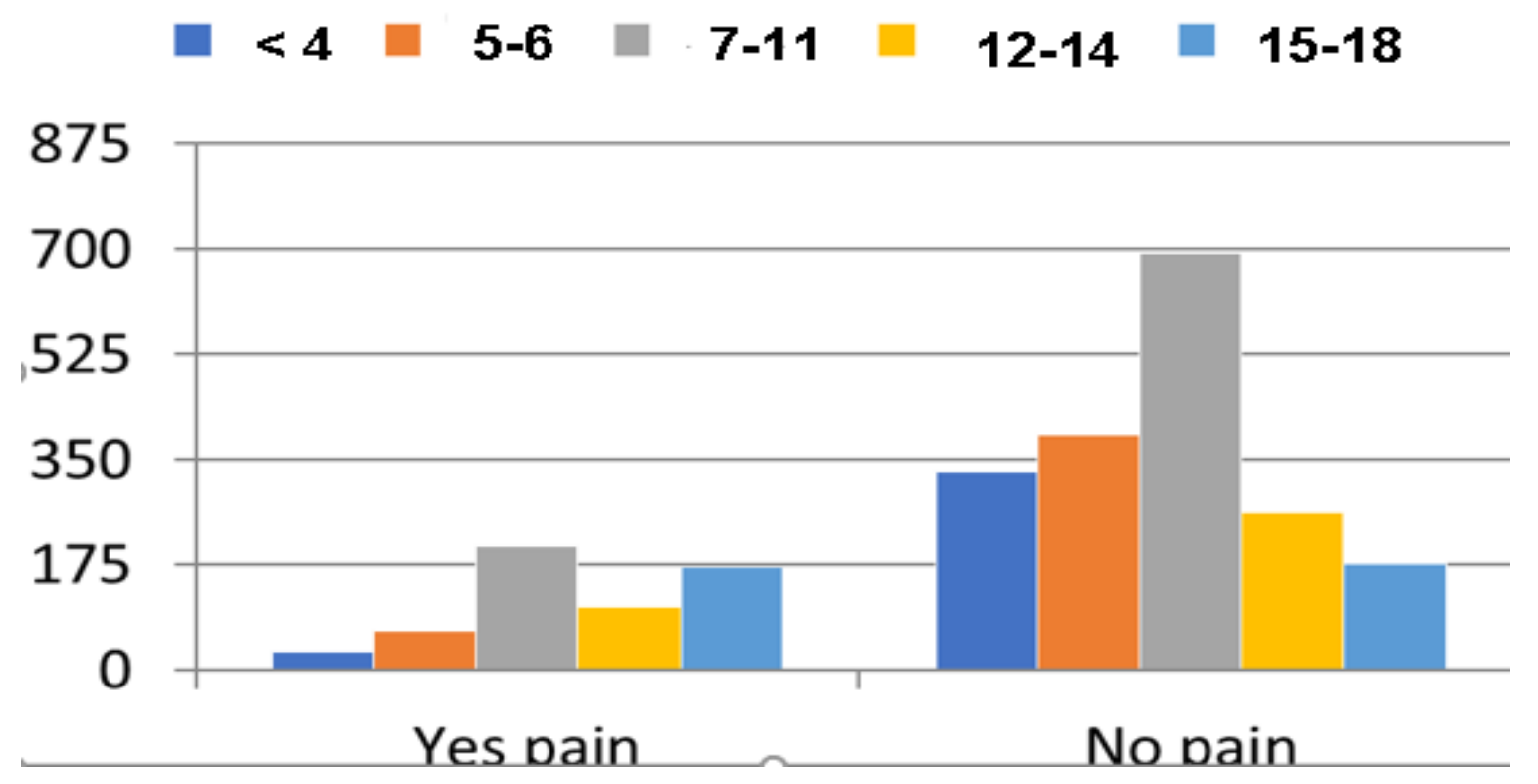

Fig. (8): Distribution of neck pain among included participants from different ages.

Comparative analysis of neck pain with other variable

All values are represented as $\mathrm{n}(\%), \mathrm{P}$ value $<0.05$ taken as significant

\section{DISCUSSION}

Our study measured the correlation between using Electronic Devices (smartphones, computers and others) and neck pain in considering sex, posture, age, and usage characteristics.

Children aged 7-11 years reported the most amount of neck pain. We believe that this is because children in this age range are stubborn, difficult to guide, and seeking independence. It is at this age that they also develop a meaningful relationship with smartphone use (texting friends, using social media, playing online games, etc.). Different position, and different pediatric age group. Other studies showed that adults and children complain from neck pain also the adolescence who use it from long time showed high significant association with neck pain and other complications ${ }^{(\mathbf{9}, 10)}$.

The results participations were mostly made by mothers, which may give incorrect data driven by "concern" due to the caring nature, and overprotection of a mother towards her child

Where the age 7-11 being the top sufferer 90 (\%) it makes perfect sense as it is the Late childhood crashes. With Early-Adolescence age, where smartphone-dearest relationship starts, and the kid becomes difficult to guideas a kid adjusts to enter adult's life as he/she starts seeking more selfdependence, where they get to look more like adults.
However, most of the studies showed that the complications are more among adults than children and associated with neck pain and other musculoskeletal pain ${ }^{(\mathbf{1 1}, \mathbf{1 2})}$.

Although we can observe a somewhat poor over watch or limited-guidance, as the highest percentage in time consumed by e-Devices was a long 5-8, but according to one study kids used to spend 3-hours on screens-in-general in 1995 and 6.5-hours in 2015. So, the double in time wasted can be related to the technological advancement in virtual reality games, vast and rapid applications that have appealing marketing, not to mention of course the dramatic fall in traditional-Television watching.

The study demonstrated that out of the 573 (23.7\%) units who reported pain, only $33(5.8 \%)$ thought it was linked to the smartphones usage, though $422(73.1 \%)$ of them went to a doctor seeking advice about neck pain. Males were slightly more than females in pain reporting 325 (56.3\%) VS $252(43.7 \%)$, probably due to the personality differences, and restrictions applied on girls .

We observed that the youngest samples had the least pain reporting $30(5.2 \%)$, probably due to parents control, and age-specific interests. In contrast, early $206(35.7 \%)$, and late 171 (29.6\%) 
Adolescents had the highest pain reporting respectively .

Amount of time spent on devices had no relativity in point of more time spent entails more hurt, and that was may be as a result of sub-focused survey questions about: (how the devices are used, it's dimensions, and holding method, weight, position, and flexion degree of the c-spine while being on the phone).All of these areas needs further exploration.

In 2016, Sang In Jung conducted a study in Daegu University, South Korea published on PubMed taken from fifty volunteers using the eDevices daily.It showed that using a smartphone for a prolonged duration could negatively affect posture; therefore predisposing the users to vertebral diseases, and neck pain ${ }^{(13)}$. Moreover, in 2016 a study conducted at Korea,Kyungnam University with 34 participants in their 20s age, showed that $18.8 \%$ experienced musculoskeletal pain related to the usage of smartphones ${ }^{(\mathbf{1 4})}$. These results were also presented among other studies regarding the neck pain and its relation with using e-Devices for long periods ${ }^{(15,16)}$. Further analysis concerning how the devices are used, their dimensions, holding method, weight, position, and flexion degree of the c-spine while excessively using a phone is needed.

\section{CONCLUSION}

One limitation of this study was that most responses were made by children's mothers. This may produce biased results due to mother's caring and over-protective nature.

Children's use of e-devices is associated with neck pain. Specifically, the more time children spend using e-devices, the more likely they are to complain about neck pain.

\section{REFERENCES}

1.AlAbdulwahab SS, Kachanathu SJ and AlMotairi MS (2017): Smartphone use addiction can cause neck disability. Musculoskeletal care, 15:10-12.

2.SHA (2011): The Saudi general authority for statistic. Available at: https://www.stats.gov.sa/en.

3.Kwok SWH, Lee PH and Lee RLT (2017): Smart Device Use and Perceived Physical and Psychosocial Outcomes among Hong Kong Adolescents. International Journal of Environmental Research and Public Health, 14:205.

4.Hysing M, Pallesen S, Stormark KM, Jakobsen R, Lundervold AJ and Sivertsen B (2015): Sleep and use of electronic devices in adolescence: results from a large population-based study. BMJ Open, 5:e006748.

5.Dorner TE and Crevenna $R$ (2016): Preventive aspects regarding back pain. Wiener medizinische Wochenschrift, 166:15-21.

6.Jung SI, Lee NK, Kang KW, Kim K and Lee DY (2016): The effect of smartphone usage time on posture and respiratory function. Journal of physical therapy science, 28:186-189.

7.Kim SY and Koo SJ (2016): Effect of duration of smartphone use on muscle fatigue and pain caused by forward head posture in adults. Journal of physical therapy science, 28:1669-1672.

8.Murphy S, Buckle $P$ and Stubbs D (2007): A crosssectional study of self-reported back and neck pain among English schoolchildren and associated physical and psychological risk factors. Applied ergonomics, 38:797804.

9.Silva GR, Pitangui AC, Xavier MK, Correia-Junior MA and De Araujo RC (2016): Prevalence of musculoskeletal pain in adolescents and association with computer and videogame use. Jornal de pediatria, 92:188196.

10.Xavier MK, Pitangui AC, Silva GR, Oliveira VM, Beltrao NB and Araujo RC (2015): Prevalence of headache in adolescents and association with use of computer and videogames. Ciencia \& saude coletiva, 20:3477-3486.

11.Xie Y, Szeto G and Dai J (2017): Prevalence and risk factors associated with musculoskeletal complaints among users of mobile handheld devices: A systematic review. Applied ergonomics, 59:132-142.

12.Obembe AO, Johnson OE, Tanimowo TO, Onigbinde AT and Emechete AA (2013): Musculoskeletal pain among undergraduate laptop users in a Nigerian University. Journal of back and musculoskeletal rehabilitation, 26:389-395.

13.Pew Research Center: Internet ST (2017): Mobile Fact Sheet. Available at: http://www.pewinternet.org/factsheet/mobile/.

14.Hakala P, Rimpela A, Salminen JJ, Virtanen SM and Rimpela M (2002): Back, neck, and shoulder pain in Finnish adolescents: national cross sectional surveys. Bmj., 325:743.

15.Shan Z, Deng G, Li J, Li Y, Zhang Y and Zhao Q (2013): Correlational analysis of neck/shoulder pain and low back pain with the use of digital products, physical activity and psychological status among adolescents in Shanghai. PLoS One, 8:e78109.

16.Ezzat HM, Al-Sultan A, Al-Shammari A, Alyousef D, Al-Hamidi H, Al-Dossary N, et al. (2015): Prevalence of neck pain among cabin crew of Saudi Airlines. Journal of back and musculoskeletal rehabilitation, 28:425-431. 